\title{
El Orgullo en Trabajo Social: Mujer, poder, conocimiento y profesión
}

\author{
Maribel Martín Estalayo ${ }^{1}$
}

\section{Recibido: 07/11/2017 / Revisado: 16/11/2017 / Aceptado: 17/01/2018}

Resumen. El siguiente artículo es una relectura de la historia del Trabajo Social en España a partir de los hilvanes que se pueden reconocer en la configuración de la profesión y la disciplina. Arte/tékhne, transición y ciencia/episteme, componen los tres momentos históricos por los que transita la joven disciplina del Trabajo Social en nuestro país. Mujer, poder, conocimiento y profesión son los hilvanes que sujetan esa historia y lucha colectiva por el lugar y la valoración en la sociedad y entre las disciplinas sociales. El objetivo principal que atraviesa estas páginas persigue un ejercicio retrospectivo como modo necesario para vivir la identidad profesional con orgullo; esto es, reunir, expresar, celebrar y mantener una autoestima adecuada que ayude a las trabajadoras sociales a enfrentar los desafíos actuales en el campo académico y en el campo profesional.

Palabras clave: mujer; poder; Trabajo Social; conocimiento; historia.

\section{[en] Pride in Social Work: Woman, power, knowledge and profession}

\begin{abstract}
The following article is a re-examination of the history of Social Work in Spain based on the threads that can be recognised in the structure of the profession and the discipline. Art/tékhne, transition and science/episteme make up the three historical phases through which the young discipline of Social Work has passed in Spain. Woman, power, knowledge and profession are the threads from which that history and collective fight for a place and value in society and in the social disciplines are woven. The main aim of this article is to engage in a retrospective exercise as a necessary means to experience professional identity with pride; that is, to assemble, express, celebrate and maintain an appropriate self-esteem that helps social workers to face current challenges in the academic and professional fields. Key words: woman; power; social work; knowledge; history.
\end{abstract}

Sumario: Introducción. 1. La tékhne: la concepción del Trabajo Social como arte. 2. Crisis profesional y transición hacia el conocimiento científico. 3. La episteme: la cuestión sobre el objeto. 4. Conclusiones. 5. Referencias bibliográficas.

Cómo citar: Martín Estalayo, M. (2018) El Orgullo en Trabajo Social: Mujer, poder, conocimiento y profesión, en Cuad. trab. soc. 31(2), 309-320.

\section{Introducción}

Pensar y reconocer el Trabajo Social con "orgullo" puede ser percibido como un gesto de arrogancia, vanidad o exceso de estimación propia si nos quedamos con su acepción etimológica más inmediata. En este sentido de la palabra, la autora ha podido escuchar en ocasiones y literalmente que la identidad del
Trabajo Social es un tema corporativista, entendiendo el poder como algo negativo - desfasado o zombi - intento de revivir algo muerto. Sin perseguir ningún tipo de representatividad, esas interpretaciones proceden de sociólogos y antropólogos, o de trabajadores sociales cuyos cursos-puente, segundos ciclos de licenciatura o doctorado les sitúa en dichas disciplinas. Todos estos hombres ocupan espacios en Tra-

\footnotetext{
Universidad Complutense de Madrid, España

mmestalayo@ucm.es
} 
bajo Social, académicos o profesionales, y, a la vez, defienden la transdisciplina o la transprofesión, lo común, como algo superior y a la vanguardia.

Pero hablar del Trabajo Social con orgu1lo, y así se plantea en estas páginas, nos conecta también con una segunda acepción -no recogida en la Real Academia Española- que refiere a un sentimiento de satisfacción sobre algo propio, una valoración o un mérito sobre algún elemento constituyente, el respeto y el amor a uno mismo ${ }^{2}$. En esta semántica se inscribe el surgimiento de distintos movimientos sociales $^{3}$ que en algún momento de la historia reivindicaron su lugar y su valoración en la sociedad: el Orgullo Negro, el Orgullo Gay, el Orgullo LGTB, el Orgullo Feminista. Todos estos movimientos también sufrieron en algún momento la incomprensión antes descrita.

$\mathrm{Y}$ en este mismo sentido del término y de la lucha como sujeto político, se reivindica o al menos se invita a reflexionar en este artículo sobre el Orgullo de ser trabajadora social. La necesidad de reclamar el Trabajo Social con orgullo se justifica en el análisis de los discursos de una investigación doctoral ${ }^{4}$ donde la falta de autoestima y valoración de las trabajadoras sociales de este país se identifica como un elemento que está afectando a su concepción disciplinar y su desempeño profesional. Esta autovaloración construida socialmente, pues la identidad se sostiene entre imágenes atribuidas y asumidas, está intrínsecamente relacionada con el hecho de ser una profesión femenina y una joven disciplina que aún tiene mucho que demostrar en el campo de la epistemología. Por lo tanto, mirar con orgullo la historia del Trabajo Social en nuestro país y reconocernos en los hilos que nos sujetaron hasta el presente, es un comienzo y una caricia para consolidar una autoestima adecuada y necesaria ante los nuevos desafíos sociales.
Estrenado el nuevo milenio y fruto de la lucha colectiva en Trabajo Social se han alcanzado todos los grados académicos posibles: grado, máster y doctorado. Conquista no exenta de conflictos e incertidumbre, dada la nueva coyuntura de planes varios de re-estructuración en la Educación Superior ${ }^{5}$. Además, tener lugar en la academia interpela a la joven disciplina con nuevos retos en la generación de conocimiento y en competencia con los de las ciencias sociales de mayor trayectoria en la historia de la universidad. De igual manera sucede con el aumento y la variedad de actores en el ámbito de la intervención social y el nuevo, cambiante y complejo terreno donde situarse y reconocerse. En definitiva, estos desafíos nos hablan de lugar y valoración, esto es, del espacio ocupado y del reconocimiento de los demás: ciudadanos, otras disciplinas, otros profesionales, instituciones, sociedad; y del propio reconocimiento y en consecuencia: ¿me siento orgullosa de lo que soy? ¿valoro mi hacer en la sociedad?

El análisis del lugar y la valoración a lo largo de la historia, se hilvana y trenza con los hilos: mujer, poder, conocimiento y profesión. Ya que la identidad del Trabajo Social la construyeron unas mujeres, que conscientes de su poder y mediante el desarrollo de su conocimiento y sensibilidad ante el sufrimiento y la desigualdad social, intervinieron en la realidad a través de una profesión. La historia del Trabajo Social está escrita en femenino. El argumento o la variable de género es imprescindible en un análisis sobre las relaciones de poder y desigualdad, y lejos de ser un argumento emocional invalidante - como en ocasiones se escucha- es una evidencia científica. No obstante, no estaría de más situar el argumento emocional junto al racional como fuente de saber. No hacerlo se explica también en un análisis de género riguroso.

\footnotetext{
De hecho, Aristóteles en la Ética a Nicómaco distingue entre el orgullo como vanidad y orgullo. Este último representa "la corona de las virtudes". Es necesario tener orgullo si uno se respeta a sí mismo. A diferencia del cristianismo, la humildad generalmente se asocia, en su pensamiento, a las "almas pequeñas". Claramente un orgullo basado en nada implica un vicio porque se trata más bien de arrogancia. En palabras de Richard Taylor (1995), el orgullo en sentido positivo se puede definir así: The nature of genuine pride is thus clear. It is the love of oneself that rests upon some strength or excellence-some virtue, in the ancient sense of that term-which is not common to all, something that enables its possessor to stand out among the multitude (p. 32).

3 Movimientos sociales compuestos por hombres y mujeres que, en alguno de los casos, en su desarrollo y evolución las mujeres $\mathrm{u}$ otros colectivos menos representados tuvieron que emprender y reivindicar un nuevo movimiento, al experimentar un trato o status desigual dentro del derecho conquistado.

4 Martín Estalayo, (2013). La investigación se elaboró a partir de la participación de 44 profesionales del área geográfica de Madrid (España) que, mediante técnicas cualitativas como son el grupo de discusión y la entrevista en profundidad, reflexionaron sobre su identidad profesional. Dicho trabajo de campo se realizó entre 2011 y 2012.

5 Léase \#Yosoytrabajosocial: construcción del movimiento estudiantil (Muriel Saiz y Gónzalez Abad, 2017)
} 
"Memoria y promesa" constituyen conceptos centrales en el título de uno de los capítulos de la obra Caminos hacia el reconocimiento de Paul Ricoeur (2005). Poder acordarse y poder prometer son las dos capacidades que se activan en la dialéctica del reconocimiento. Reconocer el Trabajo Social en nuestro país es, en primer lugar, hacer alusión a la memoria, a su pasado, a la herencia común. Esta co-herencia contribuye a la comprensión del presente y nos puede impulsar hacia planteamientos futuros. Pensar en la identidad sin memoria no es posible, puesto que habría que reinventarse continuamente cual mal endémico. Asimismo la identidad es prospectiva, compromete, mira al futuro. La promesa requiere capacidad para su cumplimiento. Prometer es comprometerse con una acción futura $\mathrm{y}$, a diferencia de la memoria, esta actuación nos remite a la alteridad, al otro. Nos comprometemos con alguien y ante alguien, un receptor que escucha la promesa y espera a que la acción se materialice. Prometer es también calibrar los compromisos y su posible realización en el tiempo, así como saber que no se pueden prometer sentimientos -por su carácter involuntario- sino solamente acciones -hacer y dar-. Por eso, advierte Ricoeur, no conviene "presumir del poder ni prometer demasiado" (p.140). La traición, enemiga de la promesa, tiene su espacio privilegiado si no se tienen en cuenta todos estos elementos que debilitan la capacidad de efectuar la promesa y la palabra.

Para el análisis de la historia del Trabajo Social en España, nos hemos apoyado en la reflexión clásica sobre el saber práctico y el teórico, que recorre toda la historia de la epistemología, desde Jenofonte a la actualidad. Uno de esos modos se identifica como tékhne $(\tau \varepsilon ́ \chi v \eta)$-arte- y así hemos titulado el primer momento: la concepción del Trabajo Social como arte. El Trabajo Social nace y se desarrolla a través del arte con el fin de mejorar, sistematizar y superar las prácticas de la experiencia caritativa. Como todo conocimiento práctico, se le presupone también un grado de conocimiento teórico. El arte no es solo una habilidad sustentada en la experiencia -hacer ciertas cosas y de tal manera-, sino que es saber hacer las cosas y por qué se hacen; busca la verdad precisamente en la práctica. El arte de alguna manera transciende la experiencia particular a través de su acción y persigue un saber universal y comunicable. El segundo momento, la crisis y transición hacia el conocimiento cientifico, se encuentra a medio camino entre la consolidación de la técnica y las primeras preguntas sobre la ciencia. Distingue esta etapa la búsqueda y demostración de un conocimiento técnico suficiente que avale un lugar en el espacio de las profesiones de ayuda. Muchos hablan de desarrollo, expansión y profesionalización del Trabajo Social cuya legitimidad social se alcanza por la participación en la política y legislación social del país, la creación de los servicios sociales y la inserción en el espacio universitario, entre otras. Es un tiempo orientado a afianzar la técnica, el método y los procedimientos operacionales, una transición hacia el conocimiento científico puesto que trata de perfilar y definir los campos de actuación, los problemas, los colectivos, las funciones profesionales, ajustadas a la concepción empírica -objetiva y avaloradoraque predominaba en la época; y, lo más importante, es el momento en el que el objeto del Trabajo Social aparece como preocupación en la profesión.

Es esta preocupación la que nos sitúa en el tercer momento, la episteme: la cuestión del objeto. La pregunta sobre el objeto del Trabajo Social nos adentra en un nuevo terreno, el modo del saber referido a la ciencia. Al igual que la tekhné, la ciencia se pregunta sobre los porqués universales, pero quiere ir más allá, desea responder por qué necesariamente el objeto es así y no de otro modo. En gran medida se trata de una labor de demarcación, qué compete a quién o a qué (Popper, 2008) y qué se encuentra dentro de ese ámbito definido como objeto de investigación. Para poder desarrollar esta tarea de demostración, el único camino que seguir es el de la justificación, esto es, precisamos elaborar, a través de distintos actos mentales, aquella estructura que dé cuenta de la propiedad del objeto.

Los distintos planteamientos que se van a presentar en este artículo dan cuenta del esfuerzo reflexivo realizado por muchas trabajadoras $\mathrm{y}$ trabajadores sociales relevantes en nuestra profesión. Todo ello compone un nuevo viraje, una invitación a profundizar en el objeto de nuestra profesión que, sin perder de vista lo conquistado hasta el momento a través del modo del saber de la tékhne, incorpore nuevos modos de conocimiento para su desarrollo y, por ende, responder con orgullo y mayor capacidad a la encomienda de la sociedad actual. En realidad se trata de introducir un valor, el 
orgullo, en la ciencia, siguiendo de alguna manera las tesis de Echeverría (2002).

\section{La tékhne: la concepción del Trabajo Social como arte}

Toda disciplina, como cualquier saber práctico, responde a las influencias de su entorno social. Comprenderla exige dialogar con las artistas -las trabajadoras sociales- y observar los contextos que inspiraron su manera de mirar la realidad; es decir, el lugar en que la obra adquiere originalidad y sentido. La disciplina del Trabajo Social, entendiendo como disciplina una formalización reflexionada y técnica $^{6}$, nace en un tiempo donde la acción social se transforma en intervención social por responsabilidad del Estado. Así, situamos el comienzo de la historia del Trabajo Social de España en la segunda mitad del siglo XIX, periodo de estabilidad y paz representado por una cultura liberal donde conviven distintas posiciones ideológicas. Entre el final de este siglo y el comienzo del siguiente se crearon las condiciones para la modernización y surgió la preocupación en distintos grupos ideológicos por la "cuestión social", el "problema social", la "reforma social" y el "deber social", en un clima europeo impregnado por la filosofía marxista y el socialismo. Los pensadores y políticos observaron los problemas sociales y las soluciones ofrecidas. Descubrir la insuficiencia, inoperancia y reducción de las soluciones al precepto legal sobre unos privilegios injustificados fue la ventana hacia la complejidad del problema y la actualización de las soluciones. Esta toma de conciencia justificaba la necesidad de una intervención social o, lo que muchos llamaron, un ejercicio del "deber social" (Azcárate, 1946).

En este contexto regeneracionista, de tensiones y acuerdos, de actualización de concepciones y acciones, de apertura y participación en el extranjero, nace la obra artística del Trabajo Social en España al amparo de la Segunda República Liberal. La primera Escuela de Trabajo Social inicia sus clases en Barcelona, el 3 de noviembre de 1932. No es extraño que la iniciativa surja en la región de España más industrializada y con una potente burguesía donde la cultura, la formación del pueblo y la apertura al exterior eran una prioridad; que fuera una formación aconfesional, a pesar de ser una filial de la Escuela Católica de Bélgica de 1920; que se asentara en una ideología de conciencia sobre las injusticias sociales, la cultura obrera y sus condiciones de trabajo, el contacto con la miseria y las necesidades y al tiempo el deseo de superar la práctica caritativa (Ferrer, 1982).

En la Revista Treball Social, María Estrada, una alumna de la primera promoción, nos presenta una fotografía sobre aquellas aspirantes a la formación de asistente social:

La mayoría pertenecíamos a las clases alta o media-alta y nos matriculamos en la Escuela para adquirir una cultura más amplia, sobre todo en unos temas de los que nada sabíamos. No pensábamos en que pudiéramos tener una perspectiva de trabajo (Ferrer, 1982, p. 13).

La Escuela estaba abierta a hombres y mujeres, pero se constituyó como una carrera eminentemente femenina. La mujer burguesa de finales del siglo XIX tejía un lento proceso de inserción en un espacio público masculinizado. El camino elegido o, más bien, predeterminado para esta inserción se hizo a través de las profesiones del ámbito de la medicina o la higiene social donde la mujer, por sus dotes y habilidades, ya estaba reconocida socialmente. La relación entre emancipación femenina y la ciencia social

Son el resultado de una grieta abierta en el orden social establecido y de los cambios radicales que se produjeron en la estructura de la sociedad; $y$, de hecho, el interés general en los problemas sociales a que dieron lugar esos cambios ayudó mucho a la causa femenina (Klein, 1971, p. 52).

El perfil de estudiante, mujer y burguesa, no hacía desmerecer la formación ofertada, exigiéndose una importante disposición a la reflexión intelectual. De las sesenta estudiantes que comenzaron el curso, cuyo acceso era una prueba de conocimiento general y dominio de idiomas, menos de un tercio superaron el primer año; y, de ellas, "fueron doce las que se diplomaron formando la primera promoción de Auxiliares Sociales" (García

\footnotetext{
En este contexto se entiende disciplina como un ámbito de conocimiento interdisciplinar -concurren otras disciplinas como el derecho, la teoría política, sociología, psicología...-y al tiempo especializado por el ámbito propio de aplicación.
} 
Guardiola, 1936). La formación duraba tres años y

Seguía el plan de Enseñanza belga, que era muy completo, el profesorado que participaba en la Escuela tenía gran prestigio. Había personas de todas las ideologías, catedráticos casi todos. Las clases se impartían mañana y tarde. Recuerdo que el segundo curso lo seguíamos en diferentes especialidades y sobre el terreno (Barenys y Jutglar, 1976, pp. 19-20).

La formación teórica tenía una finalidad y orientación técnica y trataba de capacitar a las profesionales para la futura intervención social bajo una perspectiva preventiva en el tratamiento de las problemáticas. El campo de la sanidad y la empresa fueron los primeros donde se insertaron las asistentes sociales y progresivamente encontraron su lugar, aún con dificultades, en otros campos como el de la educación. Pero, al terminar su formación, esta promoción de asistentes sociales tropezó con la primera dificultad: su identidad profesional: ¿Quiénes eran, para qué servían, cómo explicar el beneficio de su acción y dónde desarrollarla? Nos cuentan que la mayoría encontraban trabajo

Pero siempre luchando con una gran incomprensión. Unos nos aceptaban como visitadoras, otros querían que les solucionásemos problemas que no nos concernían. Resultó difícil abrirse camino sobre todo en el campo de la empresa (...) los patronos tenían miedo de que armáramos jaleo (p. 20).

Pero la Guerra Civil interrumpió en 1936 y con ella se detuvo la actividad docente.

En octubre de 1939 se reorganizaron las clases, pero en aquel tiempo se hizo cargo de la Escuela la Acción Católica y la dirigieron unas señoras que en materia de religión y aún más en problemática social, su mentalidad parecía situada en el siglo pasado (Ferrer, 1982, p. 13).

Con la dictadura, el contexto sociopolítico cambia y el Trabajo Social, siempre en sintonía con su tiempo, se ve modificado. Tras la guerra civil y el régimen franquista se vive un tiempo de paralización ${ }^{7}$. Un estudio realizado por el Departamento de Trabajo Social y Servicios Sociales de la Universidad Complutense de Madrid sobre las tesinas de fin de estudios entre 1938 y 1983 (AA.VV., 2010), refleja esta reducción del problema social al aspecto espiritual y moral. Lentamente esta concepción religiosa y moral va tomando conciencia de la necesidad de tecnificar sus modos para mejorar sus prácticas caritativas. No basta con la acción de la buena voluntad o espontaneidad, precisa una formalización ${ }^{8}$ que las supere.

En este periodo la técnica, como modo de saber, es el fundamento en el desarrollo de la acción social y la identidad profesional. Pues refiere al saber hacer las cosas y para qué hacerlas, preocupación que acompaña a la primera Escuela de Trabajo Social de la Segunda República y a las de la Dictadura: cómo realizar de la mejor manera posible una idea. Esa idea, la lucha de clases o la caridad, diferenciará las prácticas profesionales. Pero lo común es superar la experiencia espontánea y conseguir una experiencia tecnificada en pos del objetivo ideológico. Persiste un perfil feminizado. No solo la Iglesia toma las riendas como principal responsable de las Escuelas de Asistencia Social, sino que también el Estado participa y contribuye con algunas escuelas enmarcadas en la Sección Femenina. En esta línea ideológica distribuidora de roles en la función pública se renombra y resignifica la formación: Escuela para el Hogar y Obras Sociales Femeninas. Además, "la categoría de los profesores bajó sensiblemente substituyéndose las primigenias inquietudes sociales por el interés apostólico" (Struch y Güell, 1976, p. 46).

Según Abella (1996), el Régimen se caracterizó por una postura política totalitarista y autárquica, haciendo desaparecer los sindicatos y, con ello, el discurso sobre la lucha del proletariado. Se trabajó por la unificación de las costumbres, los hábitos cotidianos, la moral pública y la lengua, se cerraron las puertas a cualquier influencia extranjera pero se mantuvieron las identificaciones y simpatías por aquellos países con regímenes políticos similares. En el plano ideológico, y para conseguir esa unificación de costumbres y hábitos, "la Iglesia prestaba su aliento moral al nuevo Estado, que en correspondencia le había devuelto sus privilegios...” (p. 49). Ese pacto entre Estado e Iglesia Católica, esa concepción ideológica-religiosa, atravesó la vida española.

8 Así emerge la técnica de la entrevista, la confidencialidad en la relación, las derivaciones y la coordinación entre instituciones, con el fin de introducir cambios perdurables y definitivos. Se trata de una fusión caridad-técnica, para poner las herramientas al servicio de la ideología, y así surge el término: Caridad intelectual. Es el logos, la palabra, la representación de una idea o experiencia, la que permite que una disciplina madure y progrese, que se convierta en un saber práctico legitimado, que pueda reflexionar sobre sí misma y dialogar con el resto de disciplinas. 
En 1950 se contaba con tres Escuelas de asistencia social, ubicadas en Barcelona, Madrid y San Sebastián. Y hasta 1957 aumentan a cinco los espacios formativos en estos mismos territorios, diferenciándose una de ellas en Barcelona en el curso 1952/53. Fue la primera y única escuela masculina de Trabajo Social. La disonancia estriba en que surge para capacitar a profesionales en la administración y dirección de las obras sociales. Perfil solicitado: hombres.

El periodo comprendido entre 1958 y 1964 se conoce como el de la expansión de las escuelas. La mayor parte estaban gestionadas por la Iglesia, el resto se repartían entre la Sección Femenina y algunos organismos independientes. En 1966 los estudios son reconocidos por el Ministerio de Educación y Ciencia y se insertan en la oferta educativa del Estado como Título de Nivel Técnico de Grado Medio en Asistencia Social. Aprobados por decreto ministerial, nace en 1967 en Madrid la primera Escuela Oficial. No solo existe una preocupación por el desarrollo de la técnica en Trabajo Social sino que se busca el lugar en el ámbito de la educación estatal y el reconocimiento como profesión con espacios y modos de hacer propios en el desarrollo de la sociedad.

En la década de los años 1960 los estudios tratan de visibilizar temáticas, servicios, colectivos y modos de intervenir. Encontramos textos sobre las condiciones de la vivienda, el servicio social de ancianos, la idoneidad de las cooperativas para la reforma social, el desarrollo comunitario y la planificación social, la clasificación de los problemas en torno a la naturaleza individual o colectiva -individuo, grupo familiar, grupo social y colectividad- y del campo de trabajo -sanitario, parroquial, educativo, laboral, planificación e investigación-. En las publicaciones y las tesinas se hace un esfuerzo por presentar la descripción y la explicación de los problemas mediante métodos cuantitativos desideologizados. La corriente del empirismo positivista enra con fuerza en las ciencias sociales y, por ende, en el Trabajo Social. Aprobados los estudios, se crea en 1967 la Federación Española de Asociaciones de Asistentes Sociales y esta organización promovió en 1968 el primer Congreso Nacional de Asistentes Sociales en Barcelona. Es un hecho significativo, no por su carácter iniciático, sino porque las temáticas hacen referencia intrínseca al tema de la identidad profesional. Bien es cierto que en los congresos siempre se reflexiona sobre la profesión y lo que la concierne, pero este nace, justamente, por la necesidad de poner las bases, explícitas y en común, de todas esas características identitarias que en la posteridad se irán revisando.

En primer lugar, hace patente, a través de la conferencia inaugural del sociólogo Salvador Giner, la preocupación por la "profesionalidad" y por la posición que ocupa esta profesión y su valoración en la sociedad.

El Trabajo Social padece en España de un mal (que lo agobia también algo en el extranjero): el de la falta de profesionalidad suficiente. Pero en nuestro caso el problema es de suma gravedad. Ni las autoridades ni el público saben cuál es la función del Trabajo Social y de sus practicantes, aunque hay que reconocer que esta situación va paliándose muy lentamente año tras año. Por añadidura, aquí, como en otros países, el Trabajo Social padece de un complejo de inferioridad. Como afirma Peter Leonard, en muchos lugares los trabajadores sociales muestran una excesiva deferencia por médicos, antropólogos, economistas, psicólogos y hasta por los sociólogos, al tiempo que tienen una actitud reticente ante administradores, burócratas y autoridades. Ello es, en gran manera, prueba de su inseguridad, de su status indudablemente poco claro. Además, si el trabajador social tuviera un status enteramente profesional, como lo tienen los médicos, letrados, ingenieros o economistas no sería, por lo pronto, una profesión femenina. He aquí un dato harto sintomático del verdadero status de la profesión. En un país como el nuestro en que la promoción social de la mujer está aún por hacer, esta ha comenzado a emanciparse en el terreno ocupacional a través de las profesiones subordinadas, como la de secretaria, enfermera y, digámoslo con rudeza, trabajadora social" (1969, p. 33).

Asoma con fuerza la necesidad de convertir el Trabajo Social en una disciplina de enseñanza superior para evitar su burocratización y jerarquización en las instituciones de cualquier índole y mantener, así, un grado de independencia y responsabilidad propias. Otro de los temas principales que aparece en el congreso es el de la terminología profesional. "Los términos y conceptos no maduran paralelamente en la profesión" y en España llegan traducidos del mundo anglosajón o francés sin tener en cuenta la carga valorativa que "tienen las palabras según las diferentes culturas" (Del- 
gado, 1969, pp. 37-39). En este sentido se decide cambiar la nomenclatura de asistencia social por la de Trabajo Social para superar el aspecto benéfico-asistencial que existe en el imaginario social y en su intervención social. Otro aspecto central es la relación entre estatus profesional y deontología. Se necesita acordar una ética del Trabajo Social en la construcción de la profesión. Y no al modo de fijar una serie de prohibiciones, sino, más bien, como forma de comprometerse y "manifestar públicamente las exigencias de la profesión" (Colomer, 1969, p. 68). Y por último, se reconoce la importancia de la formación en esa búsqueda de lugar y profesionalidad. El reconocimiento oficial por el Ministerio de Educación como estudio técnico de grado medio fue el primer paso para continuar la lucha por una formación de enseñanza superior.

\section{Crisis profesional y transición hacia el conocimiento científico}

Entre 1970-1980 situamos un tiempo de crisis y transición tanto en el contexto político como en la reconstrucción biográfica del Trabajo Social. Este tiempo se caracteriza por la consecución de medidas sociales de gran calado y por las transformaciones económicas e institucionales. Adoptar los principios democráticos interpelaba a la sociedad civil y a la participación ciudadana en todos los ámbitos hacia una transición paulatina, pacífica y reformista. La Constitución Española de 1978 fue la manifestación por excelencia de todos esos cambios políticos y sociales (Tusell, 2007). La década de los años 1970, denominada etapa de crisis en la profesión, fue muy importante para debatir y asentar las bases del Trabajo Social. Crisis coincidente con la proliferación de partidos políticos en contra de la dictadura y con reflexiones del otro lado del océano: el movimiento de la reconceptualización suramericana en Trabajo Social. Fue una crisis ideológica e identitaria sobre el cometido profesional, el objeto de intervención y las prácticas. En las distintas jornadas provinciales se trabaja y discute una propuesta clara: pasar de "lo individual, el casuismo, lo apolítico y el paternalismo" hacia aquellos postulados que defienden "la dignidad de la persona, su sociabilidad y su perfectibilidad" (p. 8).

Pero esta preocupación va deslizándose poco a poco, al son del contexto políticosocial hacia los campos profesionales. Ejemplo de ello son: el II Congreso Nacional de 1972 en Madrid y el III Congreso Nacional de 1976 en Sevilla. El interés del debate se centra en la elaboración de pautas y directrices teóricas para la acción social en los distintos campos donde se inserta la profesión. También, destaca en esta transición la inquietud por definir los postulados y principios operacionales y diseñar un método propio de intervención en Trabajo Social. En los inicios de los años 1970, esta preocupación metodológica se hace eco en los distintos seminarios profesionales, con la destacada participación de Montserrat Colomer y su texto,Método básico y Trabajo Social (FEEIS, 1973). ${ }^{9}$

Existe otra fecha en otro lugar clave entre estos cambios políticos y sociales: la celebración de las III Jornadas de Asistentes Sociales de 1977 en Pamplona ${ }^{10}$. A modo de curiosidad, se incorporó el voto para el acuerdo de propuestas y conclusiones generales del colectivo, que fueron elevadas a opinión pública a través de los distintos medios de comunicación ${ }^{11}$. Las conclusiones generales tienen dos aspectos fundamentales: primeramente, el estatus laboral porque se denuncia la insuficiencia y las condiciones de contratación de las asistentes sociales -desajuste entre necesidades/recursos y posición laboral

$9 \quad$ Esta preocupación motivó otras muchas publicaciones y se convirtió en una asignatura obligatoria en el curriculum formativo. Esta renovación metodológica es una búsqueda de sistematizar y superar la espontaneidad del arte de la ayuda. Y, hablar de integración, homogeneidad, unificación, método de trabajo social, supone poner en relación lo instrumental y procedimental en pro de esa construcción identitaria específica. Sin embargo, no persigue el conocimiento científico, su objetivo es la acción profesionalizada en cualquier campo y colectivo. El esquema tiene las siguientes fases: 1. Conocimiento global del campo de trabajo 2. Interpretación de los datos. 3. Plan de trabajo. 4. Ejecución y 5. Evaluación. Es un esquema flexible que ordena y se diferencia terminológicamente de otras profesiones; se cambian los términos "tratamiento" y "diagnóstico" por "intervención" e "interpretación de los datos" (Colomer, 2009), dejando atrás el método clínico utilizado hasta el momento y adaptado al trabajo social como conjunto de prescripciones individuales para la cura de enfermedades sociales. El método básico se concibe como un modo de trabajar en pos del cambio estructural.

$10 \quad$ El texto se encuentra en: "Conclusiones generales de las III Jornadas Nacionales de Asistentes Sociales para su presentación a la opinión pública”, Pamplona: [s/n], 1977.

11 Los medios de comunicación - prensa y propaganda- fueron una plataforma importante para visibilizar al colectivo profesional y su participación en la sociedad cumpliendo así la recomendación de Mary Richmond de reformar la sociedad a partir de la propaganda y la legislación social. 
en la escala administrativa-. Así se solicita el aumento de profesionales y la participación en aquellas administraciones donde es importante su presencia -por ejemplo, en los departamentos de asistencia social de algunas Administraciones o en la organización y planificación de la Dirección General de Desarrollo Comunitario-. Asimismo se anuncia el cambio de denominación profesional: de asistente social a trabajadora social. En segundo lugar se incide en la participación política y administrativa: se propone al Congreso de los Diputados una ley que regule los recursos sociales y complemente los no legislados. Se disponen para el trabajo conjunto entre el Trabajo Social y las organizaciones políticas en pos de la mejora social. Se denuncia la inoperatividad en la tramitación de prestaciones sociales por la estructura administrativa de centralización, descoordinación y burocratización de la atención social. En las conclusiones internas de las Jornadas es donde encontramos un punto de inflexión respecto a todo lo descrito anteriormente y por eso denominamos esta etapa de transición hacia el conocimiento científico. Se debate acerca del objeto de la profesión, se busca la objetivación del campo donde opera el Trabajo Social a través de unos métodos y técnicas propias. Por consiguiente, pensar en el objeto de la profesión, convertirlo en logos y estudiarlo es el primer paso para construir una episteme en Trabajo Social.

También el libro, Introducción al Bienestar social ${ }^{12}$ de Patrocinio de las Heras y Elvira Cortajarena (1979), contribuye a esta transición. Se toma el binomio necesidades-recursos como el objetivo común en todo campo y tipo de intervención ya sea individual, grupal o comunitaria. Esta definición del objeto está estrechamente ligada a aquellas otras demandas públicas que acabamos de presentar en las conclusiones de las Jornadas: la del estatus laboral y la de la participación política. Este planteamiento no está pensado desde la perspectiva funcionalista de una intervención para la adaptación sino que persigue la transforma- ción operativa. Asimismo, el bienestar social forma parte del pensamiento sobre ese objeto del Trabajo Social como consecuencia de la aplicación de recursos. Es un producto de la política social de las democracias occidentales y "es un sistema global de acción social que responde al conjunto de aspiraciones sociales de los pueblos en relación a sus condiciones de vida y de convivencia" (p. 43).

La elaboración de la Enmienda a la Constitución Española ${ }^{13}$ fue otra de las batallas en este clima de compromiso y actitud participativa. En el primer borrador no estuvieron previstas ni la erradicación de la beneficencia ni la universalidad de los derechos sociales. Los derechos sociales que se universalizaban estaban condicionados a la seguridad social y la posición laboral. Explicar, comprometerse y proteger los derechos de ciudadanía para toda la población fueron actuaciones promovidas por el Trabajo Social para toda la sociedad española. La estructura administrativa que emerge en este contexto fueron los Servicios Sociales. Es importante entender su importancia como instrumento burocrático diseñado para desarrollar y concretar la política social de un país y como instrumento se adapta a las características ideológicas de la política social del momento. En ocasiones, los caminos se entrelazan, se complementan o se confunden a causa de la porosidad de los límites y la indefinición, pero es primordial no confundir el Trabajo Social con el instrumento del que se sirve o el espacio -uno de ellos- donde desarrolla su tarea. Llovet y Usieto (1990), a este respecto, dicen que

Los centros de Servicios Sociales, por ejemplo, son al Trabajo Social lo que el hospital o la consulta a la medicina: un lugar, un espacio, una modalidad institucional y organizativa arquetípica, intrínsecamente vinculados a quienes actúan en ellos como ejercientes. Pero la medicina no se agota ni se reduce al modelo hospitalario o consultivo; el Trabajo Social tampoco a los Servicios Sociales (p. 177).

2 Este libro fue uno de los textos más importantes de su tiempo, no solo por ser el primero en España sobre el tema del Bienestar social sino porque supuso una ruptura o novedad al establecer criterios para poder estructurar la participación del trabajo social en la política social de un Estado democrático de derecho. Los criterios que se proponen, tanto técnicos como políticos, están fundamentados en la identidad y la experiencia del trabajo social y pretende contribuir a la política social bajo el criterio global de bienestar. Se defiende que, identificados y pactados los indicadores que conforman ese concepto de bienestar social, se pueden planificar y programar actuaciones coordinadamente desde las áreas y sectores específicos. Estas incursiones tan explícitas del trabajo social en la vida política ponen de manifiesto que el ejercicio de poder formaba parte de los genes de las trabajadoras sociales.

13 Esta enmienda fue elaborada por la Federación Española de Asistentes Sociales para que, en el texto de la Constitución Española de 1978, no se incluyera la beneficencia pública como práctica profesional sino que se creara un sistema de servicios públicos a partir del cual se garantizasen los derechos sociales aprobados. 
En medio de un contexto sociopolítico de transformaciones, el Trabajo Social estaba viviendo un rápido proceso de profesionalización que, como el resto de profesiones, buscaban adaptarse a la nueva organización laboral, la llamada división del trabajo, impuesta por el proceso de industrialización y el desarrollo capitalista. Esto explica la preocupación de las profesiones por delimitar su campo de actuación, obtener legitimidad social en su cometido y un grado de autonomía que permita su desarrollo. A su vez, "esta voluntad de conquistar con otros metas de bienestar social para la población, proporcionaba a los trabajadores sociales una identidad profesional harto añorada" (Zamanillo, 1987b, p. 100). Sin embargo, la conquista de ese espacio propio -los Servicios Sociales- y la legitimación de su cometido, a través de las distintas leyes y organizaciones administrativas, no termina de satisfacer a los profesionales. Aunque estos acontecimientos no agotaron la pregunta sobre la identidad profesional, la adquisición de poder ayudó a ubicarse en el espacio de las profesiones y el Trabajo Social fue avanzando poco a poco con nuevos modos de saber que mejoraban notablemente su hacer. No es baladí terminar subrayando las conquistas profesionales como la participación en la política social y en la legislación social, la creación del colegio profesional, la delimitación de un espacio propio en el Sistema de Servicios Sociales, la confección del método básico del Trabajo Social, la inserción en el espacio universitario ${ }^{14}$ y otras. Estatus, técnica, método y formación, todos ellos elementos de reconocimiento, conformaron el discurso sobre la identidad profesional durante aquellos años.

\section{La episteme: la cuestión sobre el objeto}

Entrar en el terreno de la ciencia es reflexionar sobre el objeto del Trabajo Social y sus propiedades a partir de la lógica, la argumentación y el afán por construir su episteme. Construir la episteme en Trabajo Social, esto es, el conocimiento científico, nos exige saber qué es el Trabajo Social, por qué es lo que es y es así necesariamente y no de otra forma. Así, el primer paso para pensar la episteme fue revisar el diálogo (in)existente entre el objeto y el método en España. Zamanillo (1987a) en su artículo, Reflexiones sobre el método de Trabajo Social, señala la necesaria transición desde la concepción del método como una herramienta puramente procedimental hasta la concepción del método como consecuencia de su episte$m e$. Esta segunda manera de concebir el método, en relación intrínseca con el objeto que pretende, no solo responde a la naturaleza del término sino que nos conduce a la posibilidad de aprehender y comprender la complejidad ${ }^{15}$ de la tarea del Trabajo Social y, en consecuencia, reflexionar acerca de esta relación y sus resultados. Y este desequilibrio no solo puede derivar en una incoherencia de planteamiento epistemológico, sino que acostumbra a ser una fuente de frustración para todos aquellos profesionales que no encuentren el cambio en el desarrollo de su tarea.

Toda esta argumentación acerca del método nos sirve para situar la imperiosa revisión del objeto del Trabajo Social, ya que el primero es una consecuencia y condición de posibilidad para hacer operativo el segundo, es, como su etimología indica -meta-odo- el camino hacia la meta. La pregunta es: ¿cuál es la meta profesional en este momento en España? Como se observa en las anteriores etapas, se trata de integrar y hacer participar a la profesión de Trabajo Social en el cambio y mejora social. Para ello, la definición del objeto precisa del elemento cognoscitivo que le dote de la abstracción suficiente para ser distinguido como objeto disciplinar. La autora advierte del pluralismo cognitivo del Trabajo Social a la hora de identificar su objeto: en primer lugar, intervenir en los factores que procuran malestar en la relación de las personas con su entorno. En segundo lugar, aplicar recursos para combatir las necesidades sociales que presentan las per-

14 El título universitario de Trabajo Social se creó en 1980, cuando el Congreso de los Diputados aprobó la proposición no de Ley sobre "Transformación y clasificación como universitarios de los Estudios de Trabajo Social, creación del Título de Diplomado en Trabajo Social, y transformación de las Escuelas de Asistentes Sociales" (Boletín Oficial de las Cortes Generales, de 28 de Febrero de 1980, n 161-II). Posteriormente, en 1981, el Gobierno aprobó el Real Decreto 1850/1981 de 20 de agosto.

15 El objetivo final del método básico, alentado por la reconceptualización suramericana, era conseguir la transformación estructural de la sociedad. Quizás encontremos aquí la primera de las dificultades o desequilibrios a la hora de acometer semejante tarea pues, como expresan distintos autores reconocidos del trabajo social latinoamericano, entre otros Kisnerman, resulta idealista e inalcanzable pretender el cambio estructural a través de una profesión, más aún cuando la teoría y la práctica continúan significando y utilizándose como dos realidades separadas. Así, se descubre un método que no va más allá de la ordenación de procedimientos operativos, mas estos no están ni relacionados con su objeto ni puede alcanzarlo. 
sonas. Aceptar la coexistencia de ambas definiciones del objeto, es comprender la riqueza que comportan las distintas miradas. Mas es necesario que no solo coexistan sino que dialoguen y se complementen para garantizar la mejora en la intervención. Hablar de pluralismo cognitivo es hablar de pluralismo metodológico, y todo lo que amplíe horizontes y modos de actuar, desde el Trabajo Social o las ciencias sociales, permitirá al Trabajo Social descubrir el objeto que legitime su existencia.

En esta misma sintonía, Amaia Ituarte (1988) se pregunta acerca de la identidad del Trabajo Social y su objeto de conocimiento e intervención. La reflexión apunta a la creación de los servicios sociales como "solución clarificante" 16 de la identidad profesional. La pregunta sobre la identidad había quedado en ciernes debido a la creciente mejora del estatus profesional y formativo. Sin embargo, en una España (y Europa) en crisis económica, política e ideológica, las preguntas incontestadas se reabren y siempre acontece la oportunidad de ser respondidas. Por ello, a finales de los años 1990 se propone que el Trabajo Social se mire desde el Trabajo Social, esto es, sujeto y objeto en un mismo espacio, en interrelación y con tarea de búsqueda; enunciando otra vez la pregunta sobre el objeto de la profesión y sus posibilidades y limitaciones para enfrentarlo; comprobando que las soluciones clarificantes no eliminan el problema, más bien lo niega y reaparece en la siguiente esquina ${ }^{17}$.

La pregunta sobre el objeto no solo es el camino para construir la identidad, sino que es la oportunidad de generar nuevos espacios de comprensión y el reto de la ciencia como modo de conocimiento.

No podemos, hoy menos que nunca, seguir manteniéndonos al margen del desarrollo cien- tífico. El Trabajo Social, si quiere sobrevivir como profesión, tiene que plantearse la posibilidad de hacer sus propios aportes epistemológicos $(. .$.$) tiene que afrontar, sin ambages, el$ problema de la ciencia: no solo debe de intervenir de una manera científica en la realidad social, sino que debe de plantearse el objetivo de que esa intervención produzca a su vez ciencia (Ituarte, 1988, pp. 156-157).

Este reto nos sitúa ante la inseguridad y el miedo que provoca toda crisis; y llegados a este punto hay que decidir o por dejarse abatir por los devaneos de la experiencia y huir o por afrontarla con el afán de mejorar la versión de nosotras mismas.

Y así, fruto de la aceptación del desafío epistemológico, comenzaron a aflorar trabajos reflexivos tan importantes, como el libro Para comprender el Trabajo Social, de Teresa Zamanillo y Lourdes Gaitán. Estos ofrecían líneas discursivas sobre la exigencia teórica, los elementos constitutivos del Trabajo Social, el objeto, el modelo, el método, el espacio profesional. Fueron una invitación a reconceptualizar el Trabajo Social español en el espacio de la ciencia, es una argumentación rigurosa sobre la episteme como elemento que oriente y dote de mayor sentido a la tékhne, en una reflexión renovada en torno a la responsabilidad y complejidad que una sociedad, también en cambio y crecimiento, exige al Trabajo Social.

Tras una revisión crítica de los distintos objetos $^{18}$ identificados en Trabajo Social a lo largo del tiempo por una diversidad de concepciones -funcionalismo, interaccionismo simbólico, perspectiva dialéctica, planificación de las necesidades sociales, etcétera- Teresa $\mathrm{Za}$ manillo (1999) propone el siguiente concepto-eje, con propiedad lo suficientemente abstracta y alejado del sentido común: el malestar

16 Esta denominación se toma del autor Paul Watzlawick para referirse a toda solución basada, no en la respuesta sino en la eliminación del problema y de todo lo que tiene relación con él. De esta manera, se consigue evitar la pregunta para dedicarnos a otros problemas o preguntas de distinta índole. Para el Trabajo Social, el sistema de los Servicios Sociales era esa "solución clarificante" que obviaba la pregunta sobre su objeto, y por consiguiente, sobre su identidad.

17 Amaia Ituarte, seleccionando algunas de las acepciones del término, delimita que el objeto de una profesión ha de componerse de "una materia de conocimiento, un ejercicio sistematizado de las facultades mentales y un fin u objetivo final" y, apoyada en este aserto, define el objeto del trabajo social como: "toda situación de carencia o necesidad social del ser humano, a nivel individual, familiar, grupal o comunitario que impide o dificulta: el normal desarrollo de las potencialidades del hombre, en relación a sí mismo y a su entorno; el desarrollo del entorno social de cara a la consecución del bienestar social; y que precisa de una intervención profesional sistematizada para su mejora y/o resolución" (1988, p. 154). En esta definición podemos comprobar la integración del pluralismo cognitivo antes señalado (el objeto malestar del ser humano-entorno social y el objeto necesidades-recursos sociales), de manera que puede concluir en una explicación del objeto capaz de comprender y aprehender mejor su realidad.

18 La existencia y coexistencia de diversas concepciones del objeto no refiere a la confusión o incapacidad de homogeneidad en trabajo social, más bien al contrario, la comprensión de un objeto inserto en una realidad social de tal complejidad tiene como consecuencia un abordaje pluricognoscitivo. 
psicosocial ${ }^{19}$. Eje que encarna la siguiente definición del objeto de Trabajo Social ${ }^{20}$ : "todos los fenómenos relacionados con el malestar psicosocial de los individuos ordenados según su génesis socio-estructural y su vivencia personal" (p. 29).

Se generaliza la preocupación por encontrar modelos teóricos que orienten la práctica, que soporten, encuadren y analicen los problemas sociales para la adecuación de métodos y técnicas. La inexistencia de un modelo o su falta de complementariedad e integración con el método y viceversa puede hacernos perder de vista el objeto del Trabajo Social y pervertir la respuesta profesional sobre la demanda social. Los logros que podemos encontrar llegan de la mano de trabajadoras sociales reflexivas ${ }^{21}$ que, teniendo como denominador común el discurso sobre la necesidad de construcción del saber teórico en Trabajo Social, se esfuerzan por articular con rigor todos los aspectos relacionados con la disciplina. Una numerosa literatura profesional sustenta esta voluntad de evolución en el conocimiento y representa la nueva mirada y dirección del Trabajo Social. Son muchos los trabajos, muchas las autoras y algunos autores, que componen la bibliografía fundamental de nuestro país y contribuyeron con ilusión a la episteme del Trabajo Social. Estas inquietudes y avances en el ámbito del conocimiento científico, traen consigo una nueva lucha en el espacio formativo (De la Red, 1999). Aprobada la formación de Trabajo Social, a principios de los años 1990, como titulación de primer ciclo, y reconocido su área propia de conocimiento Trabajo Social y Servicios Sociales, la siguiente lucha vino de la mano de la conversión en licenciatura. Y aunque la licenciatura nunca llegó, el trabajo llevado a cabo durante esos años no resultó estéril al coincidir con la puesta en marcha de los nuevos títulos universitarios en el proceso de Convergencia al Espacio Europeo de Educación Superior, marco idóneo que da respuesta a la demanda que el Trabajo Social venía solicitando durante estos años. En 2017 ya podemos hablar de Grado, Máster y Doctorado en Trabajo Social.

\section{Conclusiones}

La disciplina de Trabajo Social en España por fin ha alcanzado todos los escalafones posibles dentro ámbito universitario. Esto hace que, una vez superadas las exigencias institucionales y burocráticas, la tarea real, significativa y urgente, de ahora en adelante, sea la del terreno de la fundamentación, la lógica y el saber, es decir, un conocimiento epistemológico que provenga del diálogo con la realidad e intervención social en manos del profesional reflexivo. En este conocimiento enraizado situaremos el orgullo de la trabajadora social del segundo mileno y en él también el impulso para construir y reconocer una profesión y disciplina adulta, emancipada, independiente y capaz de contribuir a los nuevos retos de la sociedad. Mas en el proceso de emancipación que se pretende alcanzar ha de tenerse en cuenta en todo momento la interdependencia con el resto de las disciplinas.

Solamente podemos añadir un breve comentario: mucho tiempo en la tékhne, apenas unos años luchando por la necesidad de la teoría y hoy tenemos la posibilidad de despegar y volar en el horizonte de la episteme. Desde los años treinta hasta la democracia, la profesión no ha pasado de ser un arte en el más puro sentido del término; es decir, aquello que hace el artesano, nada que objetar al oficio pero sí al vacío epistemológico que lleva consigo este modo de obrar. Este desafío es una responsabilidad ética para el Trabajo Social presente y, por lo tanto, algo a realizar: una trabajadora social debiera tomar postura intelectual cada mañana al levantarse ${ }^{22}$.

$\mathrm{Y}$ así, el ejercicio retrospectivo y los apuntes que acabamos de proponer en este artículo descansan en el convencimiento de que: la trabajadora social reflexiva es y será digna de orgullo en la mirada de aquellas otras profesionales que al repasar los hilos que constituyeron su historia encuentren la caricia y el impulso necesario para renovar sus promesas y prácticas; la trabajadora social reflexiva es y será digna de orgullo en la mirada de aquellas

19 El concepto de malestar proviene, fundamentalmente, de la psicología dinámica y la sociología crítica.

20 Este objeto ha sido acogido y aceptado por la comunidad del trabajo social en España hasta el momento; pero el objeto, al igual que la identidad, es revisable en diálogo con el tiempo presente y futuro.

21 Entendemos que un profesional es reflexivo, como dice Sarah Banks (1997), cuando integra conocimiento, valores y capacidades; reflexiona a partir de su la práctica y aprenden de la misma; está capacitado para el riesgo y la responsabilidad moral.

22 Palabras de la trabajadora social, Rosa García Sedano, con amplia trayectoria en un coloquio con estudiantes de los Másteres Oficiales de Trabajo Social de la Universidad Complutense de Madrid, el día 30 de octubre de 2017 en el marco de la asignatura Bases epistemológicas y perspectiva histórica de la Investigación en Trabajo Social. 
personas que en algún momento de la historia entraron en contacto con su acción ética, intelectual y artesana; la trabajadora social re- flexiva es y será digna de orgullo al mirarse y reconocerse a sí misma en la historia de la humanidad.

\section{Referencias bibliográficas}

AA.VV. (2010). El imaginario del Trabajo Social en las tesinas de fin de estudios 1938-1983. Madrid: EUTS/Universidad Complutense de Madrid.

Abella, R. (1996). La vida cotidiana bajo el régimen de Franco. Madrid: Temas de Hoy Historia.

Aristóteles (2014). Ética a Nicómaco. Madrid: Alianza Editorial

Azcárate, G. de (1946). El problema social. Buenos Aires: Atalaya.

Banks, S. (1997). Ética y valores en el Trabajo Social. Barcelona: Paidós.

Barenys, M. y Jutglar, M.A. (1976). Orígenes del Trabajo Social: Cataluña, 1932. Revista de Treball Social, 63 (septiembre), 16-22.

Colomer, M. (1969). Status profesional y deontología. Memoria del I Congreso Nacional de Asistentes Sociales (Barcelona, mayo 1968) (pp.65-71). Madrid: FEDAAS .

Colomer, M. (1990). Trabajo Social en España en la década de los 70. Revista de Servicios Sociales y Política Social, 20, 6-12.

Colomer, M. (2009). El Trabajo Social que yo he vivido. Barcelona: Impulso a la Acción Social.

Delgado, M.D. (1969). Terminología profesional. Memoria del I Congreso Nacional de Asistentes Sociales (Barcelona, mayo 1968) (pp.37-44). Madrid: FEDAAS.

Echeverría, (2002). Ciencia y valores. Barcelona: Ediciones Destino

FEEIS. (1973). Método básico de Trabajo Social. Madrid: Ed. Euramérica.

Ferrer, R.M., Llopis, B. y Porcel, A (1982). 50 Aniversario de la fundación de la Escuela de Formación de AA.SS. Revista de Treball Social, 88(4), 6-19.

García Guardiola (1936). Cataluña posee la única Escuela de Asistencia Social de España. La Noche.

Giner, S. (1969). Sociología y Trabajo Social. Memoria del I Congreso Nacional de Asistentes Sociales (Barcelona, mayo 1968) (pp.23-34). Madrid: FEDAAS.

De las Heras, P. y Cortajarena, E. (1979). Introducción al bienestar social. Madrid: FEEDAAS.

Ituarte, A. (1988). De los Servicios Sociales al Trabajo Social: hacia el reencuentro de nuestra identidad profesional. Memoria del VI Congreso Estatal de Trabajadores Sociales y Asistentes Sociales (pp.147158). Oviedo.

Klein, V. (1971). El carácter femenino: historia de una ideología. Buenos Aires: Paidós.

Llovet, J. y Usieto, R. (1990). Los trabajadores sociales. De la crisis de identidad a la profesionalización. Madrid: Popular.

Martín Estalayo, M. (2013). La construcción de la identidad en Trabajo Social: análisis de una trama hilvanada por sus personajes. (Tesis doctoral: Universidad Complutense de Madrid).

Muriel Saiz, M. y Gónzalez Abad, L. (2017). \#Yosoytrabajosocial: construcción del movimiento estudiantil. Cuadernos de Trabajo Social, 30(1), 217-219.

Popper, K. (2008). La lógica de la investigación cientifica. Madrid: Tecnos.

Red, N. de la (1999). La formación en Trabajo Social en España. Cuadernos Andaluces de Bienestar Social, $5,103-130$.

Ricoeur, P. (2005). Caminos del reconocimiento. Madrid: Trotta.

Struch, J. y Güell, A.M. (1976). Sociología de una profesión. Los asistentes sociales. Barcelona: Ediciones Península.

Taylor, R. (1995). Pride: The Lost Virtue of Our Age. Nueva York: Prometheus.

Tusell, J. (2007). La transición a la democracia (España 1975-1982). Madrid: Espasa Forum.

Zamanillo, T. (1987a). Reflexiones sobre el método en el Trabajo Social. Documentación Social, 69, 69-85.

Zamanillo, T. (1987b). Fisonomía de los trabajadores sociales. Los problemas de identidad profesional. Cuadernos de Trabajo Social, 0, 85-103.

Zamanillo, T. (1999). Apuntes sobre el objeto en Trabajo Social. Cuadernos de Trabajo Social, 12, 13-32. 